\title{
Inserções parentéticas em Editoriais paulistas do século XIX
}

\section{Parenthetical insertions in $19^{\text {th }}$ century São Paulo State Editorials}

\section{Michel Gustavo Fontes}

Universidade Federal de Mato Grosso do Sul, Três Lagoas, Mato Grosso do Sul / Brasil michelfontes2002@yahoo.com.br

Resumo: A proposta geral deste trabalho é analisar, com base nos princípios teórico-metodológicos da Gramática Textual-Interativa (cf. JUBRAN; KOCH, 2006; JUBRAN, 2007), o processo de Parentetização em Editoriais paulistas do século XIX. O objetivo é descrever a configuração formal e as funções textual-interativas das inserções parentéticas encontradas nesse gênero. Os resultados revelam que, por um lado, a materialidade escrita dos Editoriais determina o modo como se formalizam as inserções parentéticas; por outro, alguns traços composicionais desse gênero em circulação no século XIX determinam a ocorrência predominante de algumas classes e/ou funções parentéticas, como esclarecimento, ressalva e manifestação atitudinal do escrevente. Palavras-chave: construção do texto; inserções parentéticas; editorial.

Abstract: Based on a textual-interactive perspective (cf. JUBRAN; $\mathrm{KOCH}, 2006$; JUBRAN, 2007), this paper aims to analyze Bracketing in Editorials published in a São Paulo state newspaper throughout the $19^{\text {th }}$ century. Its main goal is to describe the formal configurations and the textual-interactive functions of the parenthesis found in this specific genre. The results point out that (i) the written materiality of Editorials 
determines the way parenthesis are formalized, and (ii) compositional features of Editorials in $19^{\text {th }}$ century determines the occurrence of some kinds and functions of the parenthesis.

Keywords: text-structuring; parenthetical insertions; editorial.

Recebido em 27 de setembro de 2016.

Aprovado em 12 de janeiro de 2017.

\section{Considerações iniciais}

As análises e os resultados aqui apresentados desenvolvemse no interior do subprojeto Processos de construção textual: uma abordagem diacrônica, que se vincula ao Projeto de História do Português Paulista, em sua segunda fase de execução (PHPP - Projeto Caipira II). O objetivo mais geral desse subprojeto é analisar, sob perspectiva diacrônica, processos de construção textual em diversos gêneros textuais do português paulista, traçando uma comparação entre o funcionamento desses processos no século XIX e o seu funcionamento no século XX.

Recortando esse âmbito maior de investigação, este trabalho se dedica ao estudo do processo de Parentetização em Editoriais paulistas do século XIX. Com base nos princípios teórico-metodológicos da Gramática Textual-Interativa (cf. JUBRAN; KOCH, 2006; JUBRAN, 2007), o objetivo geral é descrever a configuração formal e a funcionalidade das inserções parentéticas dos Editoriais paulistas oitocentistas, ou seja, busca-se, especificamente, (i) caracterizar o modo como se materializam os parênteses nos Editoriais analisados e (ii) delimitar suas funções textual-interativas nesse gênero específico.

A proposição desses objetivos se articula a duas hipóteses: (i) primeiramente, acredita-se que a materialidade escrita do gênero Editorial influi sobre o modo como se formaliza, no texto, a Parentetização, isto é, governa, de alguma maneira, a configuração formal das inserções parentéticas; (ii) em segundo lugar, prevê-se que alguns traços composicionais dos Editoriais oitocentistas, como sua funcionalidade sociocomunicativa, determinam a ocorrência de alguns tipos de parênteses e de algumas de suas funções textual-interativas. 
Para atender a tal proposta, este artigo está estruturado em duas seções. A primeira seção discorre sobre os fundamentos teóricometodológicos do trabalho, ou seja, trata (i) dos princípios da Gramática Textual-Interativa, (ii) da noção de Parentetização aqui assumida, e (iii) da seleção de material e de parâmetros para a análise. A segunda seção sistematiza os resultados, descrevendo a configuração formal dos parênteses nos Editoriais analisados, assim como sua funcionalidade. As considerações finais encerram o trabalho.

\section{Fundamentos teórico-metodológicos}

\subsection{A Gramática Textual-Interativa}

Partindo de uma visão de língua/linguagem enquanto instrumento de interação verbal, a Gramática Textual-Interativa (doravante GTI) elege, como objeto de análise, o texto. Especificamente, a GTI preocupase, conforme Jubran (2006a), com o funcionamento da língua em contextos reais de uso e com a atualização da atividade discursiva em textos. Para tanto, a GTI busca apoio no tripé Pragmática / Linguística Textual / Análise da Conversação.

A Linguística Textual contribui com a GTI na configuração e/ou definição de seu objeto de estudo: o texto. Pautada por um enfoque linguístico-pragmático, a GTI concebe o texto como unidade resultante da interação verbal e, assim, como unidade globalizadora e sociocomunicativa, que se constitui como tal no interior de um processo interacional (cf. JUBRAN, 2006a, p. 30). Decorre disso um princípio norteador da abordagem da GTI: "os fatores interacionais são constitutivos dos textos e inerentes à expressão linguística" (JUBRAN, 2007, p. 315).

Sob a ótica da Pragmática, a GTI sustenta a primazia de uma dimensão comunicativo-interacional na descrição dos dados linguísticotextuais (cf. JUBRAN, 2006a, p. 29). Na visão da GTI, determinações de ordem pragmática, como as condições enunciativas que sustentam a interação verbal, não são desligadas da estrutura do texto, ao contrário, elas são vistas como integradas a eles; mostram-se no texto por meio das escolhas comunicativamente adequadas às situações interacionais feitas pelos usuários da língua. Admite-se, com base nessa concepção, uma sistematicidade da atividade discursiva a ponto de definir regularidades e princípios para o processamento de estruturas textuais. 
Finalmente, é por meio da Análise da Conversação que a GTI complementa seu quadro teórico para a descrição de textos falados. Segundo Jubran (2006a, p. 30), é no exame da oralidade e na abordagem de questões mais amplas a respeito da língua falada que a Análise da Conversação contribui com a GTI. Essa preocupação em buscar um quadro teórico-metodológico que fundamente a análise de textos falados toca os trabalhos reunidos em Jubran e Koch (2006), o que não é o caso deste artigo, que estuda um gênero escrito.

Com base nesses princípios, a GTI investiga a construção do texto sem dissociar "suas características estruturais da dinâmica dos processos formulativo-interacionais sistematicamente envolvidos em sua produção" (JUBRAN, 2006a, p. 31). O foco de análise recai, portanto, sobre processos textual-interativos constitutivos do texto, como a Organização Tópica, a Referenciação, o Parafraseamento, a Parentetização, a Repetição e a Correção.

É importante salientar que a GTI prima pelo "estabelecimento de classes não-discretas de elementos, baseado no reconhecimento da fluidez de limites entre elas, em virtude do equilíbrio instável das configurações discursivas" (JUBRAN, 2007, p. 317). Além disso, essa abordagem reconhece o princípio de gradiência no estabelecimento de funções textual-interativas de mecanismos e estratégias de construção do texto, segundo o qual um determinado fato textual ou processo constitutivo do texto pode desempenhar uma função interativa sem necessariamente deixar de desempenhar uma função textual; o que é cabível dentro dessa abordagem é que um fato textual ou processo constitutivo do texto desempenhe mais uma função do que outra, mas jamais elas serão vistas como excludentes entre si.

A GTI, com base nesses princípios e objetivos, define uma unidade de análise de estatuto discursivo e compatível com esses fundamentos teóricos estabelecidos: o tópico discursivo. Segundo Jubran (2006a), ao estudar a macroestrutura textual, vê-se que o processo básico de construção do texto é o da topicalidade: "ao longo de um evento comunicativo, os interlocutores centram sua atenção sobre determinados temas, que se constituem como foco da interação verbal" (JUBRAN, 2006a, p. 32). Assim, o tópico discursivo se define a partir de duas propriedades: centração e organicidade. A centração corresponde à "propriedade de concentração da interação verbal em um determinado conjunto de referentes concernentes entre si" (JUBRAN, 
2006b, p. 302), e a organicidade, por sua vez, manifesta-se nas relações de interdependência entre tópicos, estabelecidas nos planos hierárquico e linear.

\subsection{A Parentetização: processo constitutivo do texto}

Para Jubran (2006b), durante a construção de um tópico discursivo, variados elementos podem ser inseridos ao longo dessa unidade textual, mesmo não sendo coerentes a ela. Há dois tipos possíveis de inserções: (i) uma de maior extensão textual e com estatuto tópico, já que instaura uma nova centração dentro do segmento tópico em que ocorre, o que se chama de tópico inserido, e (ii) uma de menor extensão textual, que não adquire o estatuto de tópico discursivo por não projetar uma nova centração e, assim, não projetar e desenvolver um outro tópico discursivo dentro daquele que vinha sendo desenvolvido.

Os parênteses integram-se nesse segundo grupo, constituindo-se como uma modalidade de inserção, definida como breves desvios de um tópico discursivo, que não afetam a coesão do segmento tópico dentro do qual ocorrem. (JUBRAN, 2006b, p. 303)

A propriedade definidora de uma inserção parentética é, dessa forma, o desvio tópico: "um encaixe em um segmento tópico de elementos não-concernentes ao tópico discursivo desse segmento" (JUBRAN, 2006b, p. 305). O exemplo em (1), retirado de um Editorial do corpus, traz duas inserções parentéticas que evidenciam essa propriedade definidora dos parênteses.

(1) A missão que nos impuzemos é escabrosa, bem o| sabemos; tanto mais quando o nosso objectivo de es- | tudos - a sociedade brazileira actual em seu con- $\mid$ juncto - conta elevadissimo deficit no balanço de mi- | nimas e isoladas prosperidades com que confronta o $\mid$ grosso peculio de calamidades a avultar por todos os $\mid$ lados do horisonte e nos mais importantes centros da vitalidade nacional. (A Província de São Paulo, janeiro de 1875) 
Em (1), o tópico discursivo centra-se sobre a missão e os objetivos de estudos do jornal A Província de São Paulo. ${ }^{1}$ Ao avaliar a missão que o jornal assume, o escrevente encaixa um primeiro segmento não muito concernente com o tópico relevante do segmento-contexto (no caso, bem o sabemos), já que desloca a atenção do tópico para a face do próprio escrevente, isto é, desvia-se da centração do tópico discursivo ali desenvolvido para focalizar o escrevente do Editorial, que, pelo uso da primeira pessoa, figura como o jornal na condição de instância veiculadora de informações. Por outro lado, o segundo segmento parentético (no caso, a sociedade brazileira actual em seu conjunto) é encaixado dentro do tópico discursivo de modo a esclarecer a referência construída pelo sintagma objetivo de estudos, o que confere a esse segmento um baixo grau de desvio tópico, mas o caracteriza como uma breve suspensão, centrada no conteúdo do segmento-contexto.

$\mathrm{Na}$ visão de Jubran (2006b), a propriedade do desvio tópico se dá em termos graduais, ora desviando-se muito pouco do segmento tópico, ao ressaltar aspectos do próprio conteúdo tópico, como o segundo parêntese em (1), ora desviando-se bastante do tópico discursivo, ao inserir no texto instâncias da enunciação, como seus participantes (locutor ou interlocutor) e a situação comunicativa em si, como o primeiro parêntese em (1).

Se, por um lado, os parênteses se definem como desvios tópicos, por outro, eles também podem ser definidos por sua dimensão pragmática, de natureza também gradual e variável. De acordo com Jubran (2006b, p. 307-308), os segmentos parentéticos, atuando sobre a dimensão ideacional do texto, podem sinalizar relações interpessoais e materializar, no texto, a atividade interacional, contextualizando o texto construído na situação de enunciação. Em (1), por exemplo, a primeira inserção parentética marca a voz coletiva que se instaura num texto como o Editorial e qualifica essa voz coletiva para discorrer sobre o tópico, conferindo maior confiabilidade à qualificação ali descrita a respeito da missão do jornal; já a segunda inserção parentética, mesmo que pouco

\footnotetext{
${ }^{1}$ A referência ao jornal A Província de São Paulo materializa-se pela presença de

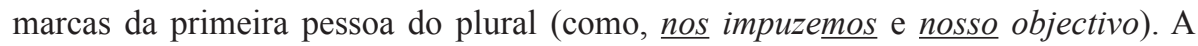
primeira pessoa do plural coletiviza o escrevente do editorial, não colocando nesse papel um único sujeito, mas todo o jornal. Trata-se, de fato, de um mecanismo de dar voz ao jornal enquanto meio de veiculação de informações e de formação de opiniões.
} 
desviante do tópico discursivo do segmento-contexto, colabora na inteligibilidade do texto, especificando o referente trazido para aquele texto, e, assim, diz respeito à cooperação entre participantes na interação para a construção de significados.

Partindo dessa variabilidade do grau de desvio tópico e da manifestação de fatores pragmáticos, Jubran (2006b; 2007) estabelece quatro classes de parênteses, gradualmente ordenadas de modo a refletir o grau de proximidade da inserção parentética ao tópico discursivo e o grau de inserção de elementos da situação interativa em que o texto é produzido: (a) parênteses focalizadores da elaboração tópica, cuja atenção se volta para três aspectos relacionados ao desenvolvimento do tópico discursivo: o conteúdo tópico, a atividade de formulação linguística ou a estruturação do tópico; (b) parênteses com foco no locutor, que materializam a presença do locutor ou escrevente no texto que produz, marcando seu posicionamento e as representações de seu papel discursivo; (c) parênteses com foco no interlocutor, que materializam a presença do interlocutor no texto, pela referência a seu papel discursivo e ao seu envolvimento não só com o escrevente/locutor, como também com o assunto em curso; (d) parênteses focalizadores do ato comunicativo, que, integrando a classe de parênteses que promovem um grau máximo de desvio tópico, provocam uma suspensão do tópico discursivo para focalizarem o ato comunicativo que está em processamento.

Assim, enquanto a classe (a) apresenta um grau maior de proximidade ao tópico discursivo e menor explicitação verbal da pragmática do texto, a classe (d) apresenta um afastamento tópico máximo e uma maior aproximação do ato interacional, isto é, uma maior explicitação das condições pragmáticas envolvidas na construção textual. A cada uma dessas classes, correspondem funções textual-interativas específicas, representadas, com base em Jubran (2006b, p. 327), no quadro 1. 
QUADRO 1 - Classes e funções dos parênteses

\begin{tabular}{|c|c|c|}
\hline \multicolumn{2}{|c|}{ Classe dos parênteses } & Funções textual-interativas dos parênteses \\
\hline \multirow{3}{*}{$\begin{array}{l}\text { (a) parênteses } \\
\text { focalizadores } \\
\text { da elaboração } \\
\text { tópica do texto }\end{array}$} & $\begin{array}{l}\text { - foco no } \\
\text { conteúdo } \\
\text { tópico }\end{array}$ & $\begin{array}{l}\text { (a) exemplificação } \\
\text { (b) esclarecimento } \\
\text { (c) ressalva } \\
\text { (d) retoque } \\
\text { (e) correção }\end{array}$ \\
\hline & $\begin{array}{l}\text { - foco na } \\
\text { formulação } \\
\text { linguística }\end{array}$ & $\begin{array}{l}\text { (a) explicitação do significado de palavras } \\
\text { (b) indicação de mudança de registro } \\
\text { (c) verbalização da atividade formulativa } \\
\text { (d) sinalização de busca de denominações } \\
\text { (e) solicitação de colaboração do interlocutor na seleção } \\
\text { lexical }\end{array}$ \\
\hline & $\begin{array}{l}\text { - foco na } \\
\text { estrutura } \\
\text { tópica }\end{array}$ & $\begin{array}{l}\text { (a) marcação de subdivisões de um quadro tópico } \\
\text { (b) marcação de retomada do tópico } \\
\text { (c) marcação do estatuto discursivo de um fragmento do } \\
\text { texto }\end{array}$ \\
\hline \multicolumn{2}{|c|}{$\begin{array}{l}\text { (b) parênteses com foco no } \\
\text { locutor }\end{array}$} & $\begin{array}{l}\text { (a) qualificação do locutor para discorrer sobre o tópico } \\
\text { (b) manifestação de interesse ou desinteresse pelo tópico } \\
\text { (c) indicação de desconhecimento do tópico } \\
\text { (d) manifestações atitudinais do locutor em relação ao } \\
\text { tópico } \\
\text { (e) indicação da fonte enunciadora do discurso }\end{array}$ \\
\hline \multicolumn{2}{|c|}{$\begin{array}{l}\text { (c) parênteses com foco no } \\
\text { interlocutor }\end{array}$} & $\begin{array}{l}\text { (a) estabelecer inteligibilidade do tópico } \\
\text { (b) evocar conhecimento partilhado do tópico } \\
\text { (c) testar a compreensão do locutor } \\
\text { (d) instaurar conivência com o interlocutor } \\
\text { (e) chamar a atenção do interlocutor para um elemento do } \\
\text { tópico } \\
\text { (f) atribuir qualidades ao interlocutor para a abordagem } \\
\text { do tópico }\end{array}$ \\
\hline \multicolumn{2}{|c|}{$\begin{array}{l}\text { (d) parênteses focalizadores do } \\
\text { ato comunicativo }\end{array}$} & $\begin{array}{l}\text { (a) sinalização de interferências de dados externos ao ato } \\
\text { comunicativo } \\
\text { (b) estabelecimento da modalidade do ato com. } \\
\text { (c) estabelecimento de condições para realização/prosse- } \\
\text { guimento do ato com. } \\
\text { (d) avaliação do ato comunicativo } \\
\text { (e) negociação de turnos }\end{array}$ \\
\hline
\end{tabular}

Fonte: Jubran, 2006b, p. 327 


\subsection{Definição do material e dos parâmetros de análise}

O material de análise deste trabalho constitui-se de Editoriais publicados no jornal A Província de São Paulo (denominado, a partir de 1889, de $O$ Estado de São Paulo), no período de 1875 a 1893 , e organizados por Lopes-Damasio e Jubran (2015) para integrar o corpus do Projeto Caipira em sua segunda fase de execução. ${ }^{2}$ Do conjunto de Editoriais reunidos pelas autoras, selecionamos quarenta, que incluem, pelo menos, dois editoriais de cada ano nesse período (entre 1875 e 1893). ${ }^{3}$

Desse conjunto de quarenta Editoriais, foram coletadas 132 ocorrências de inserções parentéticas, numa média de três por Editorial analisado. Esses dados de parênteses são analisados adotando-se alguns parâmetros definidos com base no trabalho de Jubran (2006b). Os três primeiros buscam descrever a configuração formal das inserções parentéticas, isto é, o modo como se materializam os parênteses nos Editoriais paulistas do século XIX; para tanto, analisam-se (i) as marcas formais da inserção parentética, (ii) as fronteiras de ocorrência dos parênteses e (iii) a constituição formal dos parênteses. ${ }^{4}$ Os dois últimos investigam as classes e as funções textual-interativas das inserções parentéticas, na tentativa de averiguar quais delas predominam nos Editoriais paulistas oitocentistas.

Como se intenciona sistematizar o que é predominante e mais frequente na formalização e no funcionamento do processo de Parentetização nesses Editoriais, utiliza-se o programa estatístico do pacote GOLDVARB para auxiliar na apuração das frequências e dos percentuais. Embora este trabalho não se paute por um interesse variacionista, recorrer aqui a essa ferramenta estatística se justifica exclusivamente pelo fato de ela constituir uma garantia de que todas as ocorrências serão analisadas qualitativa e quantitativamente à luz dos mesmos critérios estabelecidos.

\footnotetext{
${ }^{2}$ Lopes-Damasio e Jubran (2015) reúnem um conjunto de 204 Editoriais publicados no período de 1875 a 1893, no jornal A província de São Paulo, atual O Estado de São Paulo (cf. LOPES-DAMASIO; JUBRAN, 2015).

${ }^{3}$ Em dois anos, os de 1879 e 1891, selecionamos três Editoriais, o que nos levou ao total de quarenta Editoriais. A opção por selecionar três Editoriais para esses dois anos em específico se deu pela escassez de dados nos dois Editoriais inicialmente selecionados para esses dois anos.

${ }^{4}$ Trataremos mais detalhadamente de cada parâmetro na seção de análise.
} 


\section{As inserções parentéticas em Editoriais paulistas do século XIX}

\subsection{Formalização das inserções parentéticas nos Editoriais paulistas do século XIX}

O objetivo desta seção é entender como se materializam, na superfície textual dos Editoriais analisados e no processamento de sua estrutura textual, as inserções parentéticas. Um primeiro aspecto a se observar são as marcas formais de inserção parentética, que, segundo Jubran (2006b), funcionam, ao lado da propriedade de desvio tópico, como critério para o reconhecimento de inserções parentéticas.

No interior do segmento parentético, Jubran (2006b) registra, como marcas da inserção parentética, (i) a ausência de conectores lógicosemânticos e (ii) alguns fatos prosódicos, como pausas e alterações na pronúncia. Como o trabalho da autora tem como foco os textos falados, o critério (ii) se mostra bastante produtivo e altamente fundamental para a identificação de parênteses. Para este trabalho, entretanto, devido à materialidade escrita dos textos analisados, essas marcas prosódicas não podem ser observadas, o que faz a atenção se voltar para outro tipo de marcação, além da presença/ausência de conectores prefaciando o segmento parentético: as marcas gráficas que contribuem para a delimitação dos fatos parentéticos, como vírgulas, travessões e parênteses.

Nos Editoriais paulistas do século XIX, predominam segmentos parentéticos não prefaciados por conectores (79 ocorrências; 59,8\% dos dados). Em (2a), por exemplo, o escrevente suspende o tópico discursivo para manifestar sua franqueza em relação ao tópico discursivo; tal segmento parentético não é prefaciado por nenhum tipo de conectivo. Ocorrências de parênteses com partículas conectivas representam 40,2\% dos dados (53 ocorrências): em (2b), por exemplo, o escrevente suspende o tópico discursivo para mostrar que encara com naturalidade o conteúdo do tópico discursivo em andamento; tal segmento parentético é prefaciado pelo conectivo como.

(2) a) Nada temos, portanto com as conjecturas $\mid$ do nosso collega da Germania e, permitta- | nos a franqueza, com as suas considerações | sobre a preferencia dos professores allemães | ou de outra qualquer nacionalidade. (A Província de São Paulo, janeiro de 1886) 
b) Os $\mid$ fretes são extraordinariamente caros e $\mid$ matam o commercio, que se desforça, | como é natural, com a alta dos generos. (A Província de São Paulo, março de 1893)

Embora haja um predomínio de ausência de conectores introduzindo os fatos parentéticos, não se pode negar que é considerável (e, talvez, relevante) a frequência de ocorrências parentéticas introduzidas por esses elementos linguísticos. Esse resultado contraria uma tendência apontada por Jubran (2006b): a de que a ausência de conectivos prefaciando o segmento parentético, e, assim, a ausência de qualquer mecanismo de articulação entre esse segmento e o segmento-contexto é uma evidência da propriedade de desvio tópico.

Prefaciando os segmentos parentéticos dos Editoriais analisados, encontramos: (i) preposições, como de, com, sem e por, (ii) conjunções como se, embora e como, (iii) pronomes relativos e (iv) marcadores discursivos, como aliás, e, isto é, mas e mesmo.

$\mathrm{O}$ uso de preposições (cf. (3)) parece atender mais à estrutura sintático-semântica interna do segmento parentético e não necessariamente vincular esse segmento ao enunciado em que se encaixa (ao segmentocontexto).

(3) Cumpre que os poderes publicos to- $\mid$ mem providencias, que hoje se apresen- | tam com caracter de innegavel urgen- $\mid$ cia, para acompanharem de perto, com $\mid$ protectora vigilancia, esse progresso ex- | traordinario. (A Província de São Paulo, março de 1890)

Em (3), o segmento parentético com protectora vigilancia suspende o tópico discursivo em andamento para ampliar a referência do que se deve compreender por acompanhar de perto. Esse segmento parentético constitui-se, na verdade, de um sintagma preposicionado, e a preposição com contribui, de certa forma, para a funcionalidade do parêntese enquanto elemento de esclarecimento, ou melhor, como porção informacional que elucida e detalha alguma informação tópica, o que auxilia na clareza do enunciado e na cooperação entre escrevente e destinatário(s) na interação mediada pelo Editorial.

Desse modo, acredita-se que a ocorrência de preposições no início de parênteses não interfere na propriedade de desvio tópico por 
dois motivos: (i) primeiramente, porque os parênteses prefaciados por preposições constituem, no geral, segmentos tópicos que se voltam para a própria elaboração tópica do texto, especificamente para o conteúdo tópico, o que evidencia que o uso de preposições se dá no contexto de parênteses com baixo grau de desvio tópico; (ii) em segundo lugar, porque seu uso traz contribuições de ordem discursiva para o processo de Parentetização, isto é, para o funcionamento textual-interativo do parêntese; em (3), por exemplo, o significado de modo/maneira veiculado pela preposição com colabora com o funcionamento da inserção parentética enquanto segmento que esclarece, ao destinatário/leitor, o que o escrevente deseja evocar com o sintagma de perto.

O mesmo se aplica aos casos de parênteses introduzidos por conjunções adverbiais. Em (4), a conjunção condicional se não instaura, necessariamente, uma articulação de base condicional entre orações; ela mais reforça o caráter hipotético da objeção/correção que o segmento parentético ali insere.

(4) O anno de 1875 abre-se, pois, conservando, se não augmentando, em muitos espiritos, justas e sérias ap- | prehensões quanto á felicidade d'esta grande nação. (A Província de São Paulo, janeiro de 1875)

A oração destacada em (4), mesmo prefaciada pela conjunção condicional se, não se integra estruturalmente a outra, mas mantém uma relação adverbial com o discurso precedente. De acordo com a proposta de Decat (2001), essas orações são desgarradas, já que constituem unidades informacionais independentes. Esse traço de independência ou de desgarramento, em termos estruturais, revela que orações como (4), mesmo introduzidas por conjunções, constituem segmentos parentéticos.

Segundo Stassi-Sé (2012), estruturas independentes ou desgarradas como a de (4) apresentam um funcionamento textualinterativo que revela certo grau de desvio tópico, o que torna possível caracterizá-las como inserções parentéticas. Assim, para a autora, estruturas "autônomas/desgarradas" prefaciadas pela conjunção condicional se (cf. (4)) funcionam como salvaguardas: estruturas com as quais o escrevente busca preservar sua face ao inserir (e, assim, desviarse do tópico discursivo em desenvolvimento) uma informação da qual não tem plena certeza. 
Essa análise também se aplica aos segmentos parentéticos iniciados por pronomes relativos (cf. (5)), que são, na verdade, orações adjetivas apositivas ou explicativas (cf. DECAT, 1999; 2001).

(5) No dia em que a Gazeta de Notícias | publicou aquelle artigo O que anda no $\mid$ ar, que já resumimos nesta folha, o Dia- | rio do Commercio, que vive na intimida- $\mid$ de do governo, dizia, em artigo de [ilegível], que o Brasil está sendo ludibriado: não $\mid$ querem uma republica que se governe, $\mid$ e por isso tractam de restaurar um re $\mid$ gimen que os faça governar. (A Província de São Paulo, novembro de 1891)

Em (5), o segmento parentético que vive na intimidade do governo desvia a centração do tópico discursivo para detalhar o referente anteriormente exposto, Diario do Commercio, trazendo novas informações relevantes para o esclarecimento do que se expõe no tópico discursivo. Segundo Decat (2001), orações adjetivas apositivas, como a de (5), constituem unidades de informação à parte e, dessa forma, constituem orações desgarradas; podem ser consideradas, portanto, fatos parentéticos.

Por fim, em (6), são trazidas algumas ocorrências de fatos parentéticos prefaciados por marcadores discursivos.

(6) a) O que não fazemos, e nunca faremos, é da imprensa | um poste para os adversarios e altar para correligio- $\mid$ narios por mais peccadores que elles sejam. (A Província de São Paulo, janeiro de 1879)

b) E em bem da probidade do tribunal, mas $\mid$ não tanto em hora do dever de alta magis- | tratura, a causa attribuida é a pressa no jul- | gamento que obriga os juizes a examinarem | pouco os documentos e a adoptarem os funda- | mentos do juiz de direito. (A Província de São Paulo, janeiro de 1884)

c) Da população em edade de freguentar es- $\mid$ colas, orçada em 108,799 tambem sómen- | te um oitavo, isto é, cerca de 20 mil, fre- | quenta escolas, deixando de frequental-as | quase 150 mil! (A Província de São Paulo, janeiro de 1876) 
d) Em escripto de maior folego seria isso a liquidação philosophica e politica do passado e a denuncia pre - | vidente do porvir. Nessas rapidas linhas só póde ser $\mid$ opportuno esboço para que melhores espiritos, na cal- $\mid$ ma da consciência e no remanso do gabinete, com- | pletem a obra, aliás patriotica e capaz de fecundo en- | sinamento e urgentissimos conselhos á sociedade em $\mid$ geral e aos proprios Palinuros do Estado. (A Província de São Paulo, janeiro de 1875)

Em (6a), por exemplo, o segmento parentético e nunca faremos vem ampliar a abrangência da afirmação anteriormente estabelecida, reforçando que a declaração de não fazer da imprensa um poste para os adversários estende do momento presente (fazemos) a momentos posteriores, futuros (faremos). Trata-se, portanto, de um parêntese de ordem mais textual, com foco no conteúdo tópico, especificamente uma ressalva; pode-se, entretanto, visualizar uma atuação interacional desse parêntese, que, ao menos, age na preservação da face do escrevente, adiantando e bloqueando qualquer suposição do(s) destinatário(s) a respeito do conteúdo tópico abordado. Nesse sentido, o $e$ introduzindo tal segmento não só atua num plano textual, no sequenciamento da unidade parentética, como uma partícula de adição, mas, principalmente, constitui um mecanismo de conferir ênfase ao segmento parentético, atuando, assim, num plano mais interativo (cf. PENHAVEL, 2006).

Já em (6b), o segmento parentético mas não tanto em hora do dever de alta magistratura traz uma ressalva em relação ao conteúdo expresso pelo sintagma em bem da probidade do tribunal. O que se nota é que, assim como $e$ em (6a), o marcador mas não se presta somente à função de articulação ou de conexão, mas age sobre a conectividade discursiva, sustentando o caráter contrastivo do segmento parentético de forma a evidenciar seu estatuto de ressalva.

Em (6c) e (6d), por fim, os segmentos parentéticos detalham dados expostos no tópico discursivo, funcionando como esclarecimentos. Os marcadores discursivos isto é e aliás são, de certa forma, sequenciadores tópicos e contribuem para o significado particularizador associado aos parênteses que introduzem.

Explorar cada um dos tipos de conectivos lógico-semânticos que prefaciam as inserções parentéticas encontradas no corpus demonstra que, independentemente de sua natureza relacional, esses conectivos não 
interferem na propriedade de desvio tópico e, dessa forma, segmentos por eles introduzidos podem constituir parênteses (cf. STASSI-SÉ, 2012). Entre as 53 ocorrências de parênteses prefaciados por conectivos, 37 (praticamente $70 \%$ dos dados) são casos de parênteses com foco no conteúdo tópico, ou seja, são parênteses com um grau mínimo de desvio tópico, e alguns constituem casos de desgarramento (cf. DECAT, 1999; 2001). Além disso, é importante a contribuição desses conectivos para a significação e a funcionalidade textual-interativa dos segmentos parentéticos.

Essa análise, no geral, faz visualizar também que a considerável frequência de elementos conectivos entre os dados de parênteses coletados se deve ao tipo de interação em que circula o Editorial, uma interação que, distante da conversação face-a-face, não se apoia nas circunstâncias contextuais imediatas do aqui-e-agora. Os conectivos, assim, constituem suportes para o funcionamento das inserções parentéticas.

Em relação às marcas gráficas, ajudam a delimitar as inserções parentéticas, essencialmente, vírgulas (123 ocorrências, o que representa 93,2\% dos casos). Há alguns casos de parênteses ( 2 ocorrências; $1,5 \%$ ) e de travessão (6 ocorrências; 4,5\%) e um único dado em que aparece ponto-e-vírgula associado a travessão $(0,8 \%)$.

(7) a) O serviço que desagrada e levanta re- | clamações não é mal feito por má vonta- | de dos empregados, justiça se lhes faça, | mas por deficiencia de pessoal. (A Província de São Paulo, janeiro de 1886)

b) Quanto á demora da viagem das mer- | cadorias nas poucas estradas que temos, | porque não adoçou a pilula da censura $\mid$ (até certo ponto justa), fazendo-nos ver $\mid$ que essa demora, affinal, é uma conse- $\mid$ quencia do nosso extraordinario e ines- $\mid$ perado progresso nestes ultimos annos? (A Província de São Paulo, março de 1893)

c) Entretanto-dóe-nos o dizel-o, mas a | verdade acima de tudo-o serviço de ex- $\mid$ tincção, ha tanto tempo organisado, ain- | da é a mesma cousa rudimentar e im- | prestavel de ha muitos annos atraz. (A Província de São Paulo, março de 1890) 
d) Fallou depois o sr. Albuquerque $\mid$ Lins que desenvolveu alguns longos $\mid$ apartes 15 que havia dado nos dias ante- | riores. Fez a historia do abolicionis- $\mid$ mo para dizer que o partido liberal e | a illustre familia Queiroz são abolicio - | nistas e mais, que o partido conserva- $\mid$ dor e outros pretendem esses fó- $\mid$ ros com menos civismo;-aquelle ci- | vismo a que se referiu o sr. Augusto | Queiroz. (A Província de São Paulo, março de 1888)

Em (7), diferentes fatos gráficos contribuem na delimitação dos parênteses. Em (7a-b), a suspensão do tópico discursivo para que o escrevente demonstre sua atitude/crença de justiça em relação ao conteúdo desse tópico se delimita pelo uso das vírgulas (cf. (7a)) e dos parênteses (cf. (7b)). Já em (7c), o segmento parentético, também revelador da atitude do escrevente em relação ao tópico discursivo, delimita-se por meio dos travessões. Por fim, em (7d), combinam-se ponto-e-vírgula e travessão para delimitar a inserção parentética que esclarece a referência de um elemento do tópico discursivo.

Outro ponto que diz respeito à materialização do processo de Parentetização é a fronteira de inserção do segmento parentético. Jubran (2006b, p. 310) considera que qualquer fato parentético ocorre na fronteira entre constituintes (cf. (8a-b)) ou unidades frasais (cf. (8cd)), de forma que se possa segmentar o trecho em que ocorre a inserção parentética da seguinte maneira: E1 = segmento anterior ao parêntese, $\mathrm{E} 2=$ o parêntese e E3 = segmento posterior ao parêntese. As ocorrências em (8) seguem esse padrão.

(8) a) A approximação dos dous grupos | monarchicos, apparentemente diver- $\mid$ gentes, explica a declaração do voto | do sr. Almeida Nogueira, na questão | de confiança 40 politica no actual gabi- | nete. (A Província de São Paulo, agosto de 1889)

b) Cumpre que os poderes publicos to- $\mid$ mem providencias, que hoje se apresen- | tam com caracter de innegavel urgen- | cia, para acompanharem de perto, com $\mid$ protectora vigilancia, esse progresso ex- | traordinario. (A Província de São Paulo, março de 1890) 
c) Nessa occasião o sr. visconde do Rio Branco | prestou um grande serviço ao paiz, é verda- $\mid$ de, mas dahi não lhe veio gloria por não $\mid$ ter s. exc. tido a iniciativa da idéa. (A Província de São Paulo, agosto de 1879)

d) Si esta idéa fôr levada a effeito — e não $\mid$ cremos que encontre tropeços-ficará a $\mid$ S. Paulo a glória de se ter lembrado, pri- | meiro entre todos os Estados da nação,de | commemorar os grandes homens que por | seus feitos e por suas obras bem mere- | ceram do seu paiz. (A Província de São Paulo, agosto de 1893)

Em (8a), o parêntese se insere entre o SN sujeito (a approximação dos dous grupos monarchicos) e o SV (explica...); já em (8b), o parêntese se insere entre o SN (providencias) e a oração que o completa (para acompanharem de perto, com protectora vigilancia, esse progresso extraordinario). Por outro lado, em (8c), o parêntese se encontra entre as duas orações articuladas pela adversativa mas; em (8d), o parêntese se insere entre a oração condicional e a sua principal.

Quando interrompem a adjacência entre constituintes ou entre unidades frasais, como em (8), os fatos parentéticos suspendem o processamento do tópico sem nenhum corte sintático, e, entre E1 e E3, não há qualquer tipo de descontinuidade sintática. Em casos como (8c), no segmento E3, há a presença de um conectivo ou de um marcador discursivo para retomar o tópico suspenso pelo parêntese e progredir com o tópico discursivo a partir de E1.

De certa forma, essa sistematicidade na marcação da inserção parentética está intrinsicamente ligada à materialidade escrita do gênero Editorial, que, de certa forma, envolve um planejamento de sua atividade formulativa. O gênero Editorial, sendo um gênero escrito, é altamente planejado e elaborado, o que possibilita que se controle o modo como se formalizam suas inserções parentéticas, evitando-se, assim, inserções que interrompem, com rupturas ou cortes sintáticos, o processamento do tópico discursivo, como ocorre em (9).

(9) L1 - de vez em quando aparecem as riscas no chão marcando o início de pista...mas...na maioria das vezes tao todas apagadas o que () terrivelmente em dirigir principalmente à noite. 
L2 - isso é um problema econômico é o mesmo caso agora vai entrar o técnico pra dar a/ a satisfaçao... acontece o seguinte a sinalizaçao...é um/ uma etapa cara da estrada...mas...é indispensável à segurança de tráfego... (JUBRAN, 2006b, p. 316 , grifos do autor)

Em (9), ocorrência de um texto falado, o segmento parentético agora vai entrar o técnico pra dar a/ a satisfaçao... gera um corte sintático no tópico discursivo em desenvolvimento, de forma que há um reprocessamento da informação anterior ao segmento parentético por meio de uma estratégia de reformulação textual. Esse tipo de ocorrência não foi identificado nos Editoriais analisados, o que, a nosso ver, decorre da atividade altamente planejada e elaborada envolvida em sua construção.

As inserções parentéticas, nos Editoriais analisados, podem também ocorrer no início (cf. (10a)) ou no fim de unidades frasais (cf. (10b)).

(10) a) Em boa politica, á parte as ques- | tões de personalidades, e esquecidas | as queixas partidarias, o ministerio 7 | de Junho devia ser sustentado pelos $\mid$ conservadores evolucionistas. Era o | que a situação reclamava; infeliz- $\mid$ mente, porém, estes soffrem crúa | guerra do governo e o novo partido, | apezar da sua largueza de vistas, é | obrigado a negar apoio antecipado | ao ministerio 7 de Junho, tão con- | servador ou tão liberal como o 10 de $\mid$ Março.

A dizer a verdade, não sabemos em $\mid$ que se differenciam quanto aos prin- | cipios os srs. Affonso Celso e Pauli- | no de Souza, os srs. A. Prado e | Saraiva embora este seja federalista | que não conhece bem a distincção dos | dous programmas liberaes,o da maio- | ria do Congresso e o do sr. Ruy Bar- | bosa. (A Província de São Paulo, agosto de 1889)

b) O domingo entre nós já se vae tornando $\mid$ um perigo sério para os que atrevem-se a $\mid$ pôr pé na rua, principalmente das 4 horas | da tarde ás 10 ou 11 da noite, se é que não | correm egual perigo mesmo as familias que $\mid$ limitam-se a vir á janella. (A Província de São Paulo, fevereiro de 1876) 
Em (10a), o segmento parentético em negrito encontra-se no início de um parágrafo do Editorial. Trata-se de uma inserção parentética se considerarmos a sequenciação desse parágrafo introduzido pelo parêntese em relação ao parágrafo anterior e, além disso, se tomarmos em conta que esse segmento parentético é bastante desviante da centração do tópico discursivo pois foca a imagem do escrevente, manifestando sua atitude em relação ao tópico que está sendo desenvolvido.

Por outro lado, em (10b), o segmento parentético em negrito reformula uma informação tópica precedente. Seu grau de desvio tópico é bem menor se comparado ao de (10a), porém podemos considerá-lo uma inserção parentética.

A maioria dos segmentos parentéticos encontrados se interpõe na fronteira entre unidades linguísticas, configurando a sequência E1-E2-E3. São 86 ocorrências de parênteses entre constituintes da frase $(65,2 \%$ dos dados) e 24 de parênteses no limite entre duas unidades frasais $(18,2 \%$ dos dados), o que totaliza 110 parênteses rompendo a adjacência entre constituintes ou entre unidades frasais $(83,4 \%$ dos dados). Parênteses no fim de frase ou de parágrafo totalizam 21 ocorrências $(15,9 \%$ dos dados), e há uma única ocorrência de parêntese no início de parágrafo ( $0,8 \%$ dos dados). De certa forma, esses dados estatísticos revelam que a posição prototípica de segmentos parentéticos é na fronteira/adjacência de unidades linguísticas.

Por fim, em relação à sua constituição formal, Jubran (2006b) afirma que os parênteses são, no geral, de curta duração e podem ter as seguintes configurações formais: (i) marcadores discursivo; (ii) sintagmas nominais; (iii) frases simples; (iv) frases complexas e (v) pares adjacentes.

Constituições formais como (i) e (v) não foram encontradas entre nossos dados. Jubran (2006b), em seu estudo de textos falados, cita parênteses constituídos predominantemente de marcadores discursivos orientadores da interação, como claro?, entendeu? e digamos assim. Em textos como os Editoriais, de um discurso planejado e elaborado, em que o "modus sintático prevalece sobre o pragmático" (JUBRAN, 2006b, p. 301), não é muito fácil encontrar parênteses constituídos por esses marcadores. Assim também ocorre com parênteses constituídos de pares adjacentes, como o par dialógico pergunta-resposta, típicos de situações conversacionais, em que predomina uma interação face-a-face.

Dessa forma, nos Editoriais paulistas analisados, os parênteses encontrados se constituem formalmente como sintagmas (cf. (11a-c)), 
frases simples (cf. (11d-e)) e frases complexas (cf. (11f-g)). No que se refere aos parênteses de estrutura sintagmática, Jubran (2006b), em seu corpus de textos falados, identifica somente parênteses constituídos por sintagmas nominais; já nos editoriais analisados, além dos sintagmas nominais (cf. (11a)), encontram-se parênteses constituídos por sintagmas adjetivais (cf. (11b)) e por sintagmas preposicionados (cf. (11c)).

(11) a) No $2^{\circ}$ escrutinio do $1^{\circ}$ e $7^{\circ}$ districtos venceu $\mid$ a opposição, sendo eleito naquelle o sr. dr. An- | tonio Prado, candidato conservador, e neste o $\mid$ sr. dr. Campos Salles, candidato republicano. (A Província de São Paulo, 03/01/1885).

b) A opposição, assim constituida, ha $\mid$ de muitas vezes unir-se e embaraçar $\mid$ actos menos regulares do partido domi- | nante. (A Província de São Paulo, 11/01/1887).

c) O chefe do estado despediu os seus minis- $\mid$ tros conservadores e chamou outros, de po- | litica diversa, representantes dos matizes do | liberalismo. (A Província de São Paulo, 12/01/1878).

d) Necessitamos de uma politica practica, é certo, | mas cujos actos sejam inspirados por um ideal de- $\mid$ terminado, claro e concludente (A Província de São Paulo, 04/01/1875).

e) O que não fazemos, e nunca faremos, é da imprensa | um poste para os adversarios e altar para correligio- | narios por mais peccadores que elles sejam. (A Província de São Paulo, 04/01/1879).

f) Confiamos muito no criterio dos membros $\mid$ da commissão, entre os quaes se acha um $\mid$ que tambem se corresponde com sabios es- | pecialistas da Europa, para darmos a pater- $\mid$ nidade de actos bons sómente ao sr. D. Pe- $\mid$ dro II. (A Província de São Paulo, janeiro de 1886)

g) O mais operoso, o mais assiduo e o $\mid$ mais brilhante redactor do Commercio | de S. Paulo, o illustre sr. José Julio Rodrigues-a quem enviamos cordiaes cum- | primentos, por que é a primeira vez que $\mid$ nos encontramos-acaba de publicar, na- | quella folha, um artigo que não deve | circular sem alguns comentarios. (A Província de São Paulo, março de 1893) 
Para Jubran (2006b, p. 356), algumas configurações formais (e até mesmo funções) dos parênteses são específicas de textos falados, por conta das circunstâncias de processamento da fala, que diferem das da escrita. A autora reconhece que textos escritos prototípicos, que são altamente planejados e lapidados, não abrigam as descontinuidades que os parênteses provocam nos segmentos tópicos de textos falados, e nem mesmo as configurações formais verificados em textos falados.

Esta seção, enfim, elucida bem essa afirmação da autora em dois pontos: (i) um texto escrito como o Editorial, que ocupa um pólo extremo no contínuo fala-escrita (cf. MARCUSCHI, 2001), altamente planejado e elaborado, não apresenta parênteses que, inseridos na fronteira entre constituintes ou entre unidades frasais, interrompem a estrutura sintática da sentença e, assim, provocam descontinuidades no texto, e (ii) a materialidade escrita do texto também influi nas marcas de inserção parentética, deixando proeminente a função de conectivos lógico-semânticos na introdução desses segmentos e, além disso, fazendo uso de diversas marcas gráficas na sua delimitação.

\subsection{Funcionalidade das inserções parentéticas em Editoriais paulistas do século XIX}

Predominam, nos Editoriais paulistas do século XIX, duas classes de parênteses: a classe (a), especificamente os parênteses com foco sobre o conteúdo tópico (cf. (12a)), com 97 ocorrências (73,6\% dos dados), e a classe (d), parênteses com foco sobre o escrevente (cf. (12b)), com 32 ocorrências $(24,3 \%$ dos dados $)$.

(12) a) O anno de 1875 abre-se, pois, conservando, se não augmentando, em muitos espiritos, justas e sérias apprehensões quanto á felicidade d'esta grande nação. (A Província de São Paulo, janeiro de 1875)

b) Nada temos, portanto com as conjecturas $\mid$ do nosso collega da Germania e, permitta- | nos a franqueza, com as suas considerações $\mid$ sobre a preferencia dos professores allemães | ou de outra qualquer nacionalidade. (A Província de São Paulo, janeiro de 1886) 
Em (12a), o segmento se não augmentando focaliza o conteúdo tópico do segmento-contexto e, dessa forma, guarda uma proximidade com o tópico discursivo em desenvolvimento. Sua função, portanto, é mais textual, reformulando a informação tópica precedente. Ele não deixa, entretanto, de ter uma natureza interacional, ainda que pouco evidente: esse parêntese, ao menos, cumpre com a questão da informatividade, acrescentando, ao destinatário, uma nova informação em relação ao conteúdo tópico. Já em (12b), é por meio do segmento permitta-nos a franqueza que o sujeito escrevente se introjeta no texto que produz e traz para ele uma representação a respeito de seu papel discursivo. Sua função, portanto, é de natureza mais interacional, uma vez que o escrevente manifesta, para o destinário, sua atitude em relação ao tópico.

A predominância de segmentos parentéticos com foco no conteúdo tópico evidencia a condensabilidade do Editorial, um dos atributos fundamentais desse gênero, segundo Beltrão (1980). O Editorial, frente a tal propriedade, deve focalizar e desenvolver um único tópico ao longo do texto. Como os parênteses da classe (a) se orientam quase que exclusivamente para o tópico em desenvolvimento no texto, seu predomínio nos Editoriais paulistas do século XIX reduz a materialização e a explicitação, ao longo do texto, das circunstâncias situacionais de interlocução, o que garante a focalização apenas no conteúdo a ser abordado pelo Editorial.

Os parênteses com foco no conteúdo tópico encontrados nos Editoriais analisados apresentam quatro funções diferentes no sentido de caracterizar um referente do conteúdo tópico: esclarecimento (cf. (13a-b)), ressalva (cf. (13c-d)), retoque (cf. (13e)) e correção (cf. (13f)).

(13) a) A independente e activa provincia de S. Paulo, juiz $\mid$ de nossa conducta nas lides da imprensa, dirá se te- $\mid$ mos concorrido para seu engrandecimento e se esta $\mid$ folha corresponde a uma necessidade relativa ao seu | progresso e nobres aspirações. (A Província de São Paulo, 1879)

b) Afinal o passageiro, afflicto e maldizen- $\mid$ do do serviço e da Companhia, corre por $\mid$ sua vez a procurar a familia para acom- | modal-a. (A Província de São Paulo, 1882)

c) Duplo motivo - o novo anno e o início de nossa $\mid$ carreira convida-nos a não deixar passar o momen- | to sem algumas reflexões, genericas embora, sobre a $\mid$ actualidade do paiz. (A Província de São Paulo, 1875) 
d) Quanto á parte que nos diz respeito, não | podemos acceitar como procedentes as alle- $\mid$ gações do illustrado contemporaneo. Não | tratamos de professores allemães nem de $\mid$ preferencias pelos inglezes ou americanos : apenas extranhamos que, com a responsabi- | lidade do illustre presidente da commissão do plano de ensino, se désse autoridade ao | imperador para intervir na execução da nova | lei provincial e se attribuisse aos dous, sem | duvida cavalheiros muito distinctos, uma $\mid$ providencia que estava determinada na mes- $\mid$ ma lei. (A Província de São Paulo, 1886)

e) O domingo entre nós já se vae tornando $\mid$ um perigo sério para os que atrevem-se a $\mid$ pôr pé na rua, principalmente das 4 horas | da tarde ás 10 ou 11 da noite, se é que não | correm egual perigo mesmo as familias que | limitam-se a vir á janella. (A Província de São Paulo, 1876)

f) Tendo obtido por favor do sr. Saraiva, e | não por influencia propria, um logar na lis- $\mid$ ta tríplice da Bahia, era decoroso e de boa | lealdade que o sr. Zacharias não procurasse açodadamente empalmar a senatoria por $\mid$ meio da empalmação do ministerio. (A Província de São Paulo, 1880)

Parênteses de esclarecimento, como em (13a-b), tem por finalidade (i) detalhar a referência de algum elemento trazido anteriormente, como em (13a), em que o aposto juiz de nossa conducta nas lides da imprensa torna clara a referência evocada pelo sintagma nominal $a$ independente e activa provincia de $S$. Paulo, ou (ii) elucidar dados que contribuem para a clareza dos conteúdos ali presentes, como em (13b), em que o sintagma afflicto e maldizendo do serviço e da Companhia particulariza uma informação do contexto descrito para atender a um propósito maior do jornal, o de denúncia das condições dos serviços prestados pela companhia de trem.

Já parênteses de ressalva, como em (13c-d), servem como observações do escrevente a respeito da abrangência referencial de elementos ou conteúdos do enunciado, cumprindo, desse modo, um papel mais textual. No âmbito interativo, sua contribuição é mais restrita, já que servem, ao menos, a uma estratégia de preservação da face do escrevente, que, antecipando possíveis conclusões de seu(s) destinatário(s) a respeito da temática do tópico, já as nega. O parêntese 
em (13c), por exemplo, opera uma redução da abrangência das reflexões trazidas naquele Editorial sobre a atualidade do país: o escrevente sinaliza para o destinatário que as reflexões devem ser encaradas como genéricas; esse movimento de ressalva é uma forma de o escrevente manter sua autoimagem, uma vez que ele próprio adianta a seu(s) destinatário(s) que as reflexões tem caráter genérico. Em (13d), por outro lado, o movimento é contrário: o parêntese sem duvida cavalheiros muito distinctos opera uma ampliação na abrangência referencial de os dous, acrescentando qualificações como cavalheiros e muito distinctos; a ressalva, de certa forma, atende à preservação da face do escrevente ao trazer, para o texto, uma possível conclusão que forma parte do conjunto de conhecimentos do(s) destinatário(s).

Por fim, parênteses de retoque (cf. (13e)) e de correção (cf. (13f)) são meios de reformulação textual. O parêntese de retoque reformula uma informação tópica, acrescentando elementos diferentes a ela; em (13e), por exemplo, o segmento parentético reformula a informação sobre $o$ perigo de estar à rua no horário entre quatro da tarde e dez ou onze da noite ao inserir a informação de que igual perigo podem estar passando as famílias que permanecem à janela. O parêntese de correção, por outro lado, anula a informação sobre a qual recai a correção, como em (13f), em que se anula a informação de que se teria obtido o lugar na lista tríplice da Bahia por influência própria.

Entre os parênteses focalizadores do conteúdo tópico, predominam, nos Editoriais, os parênteses de esclarecimento e de ressalva. Estes representam 36,4\% dos dados, num total de 48 ocorrências, enquanto aqueles representam $31,8 \%$ dos dados, num total de 42 ocorrências; juntos representam 68,2\% dos dados. ${ }^{5}$ Essa predominância evidencia o caráter não só informativo do Editorial, mas também seu caráter opinativo. Ao trazer novos elementos para a construção de um referente ou de uma informação, os esclarecimentos, além de colaborarem com a informatividade e a clareza do texto, operam na construção de um posicionamento opinativo do jornal em relação a tal informação ou referente. Os parênteses de ressalva, ao restringir ou ampliar a abrangência referencial de uma determinada informação,

\footnotetext{
5 Tais porcentagens levam em conta a totalidade de dados encontrados nos Editoriais analisados, no caso 132 ocorrências de inserções parentéticas.
} 
veiculam avaliações sobre essas opiniões, o que materializa o ponto de vista do jornal em relação ao fato relatado.

Se, conforme expõe Jubran (2006b, p. 328), parênteses de esclarecimentos e de ressalva, na função de parênteses focalizadores do conteúdo tópico, asseguram a inteligibilidade e a aceitabilidade do texto e contribuem para a caracterização de um referente ou de algum elemento informacional do conteúdo tópico, sua predominância nos Editoriais analisados está relacionada ao propósito comunicativo mais geral do gênero Editorial: a defesa de um posicionamento crítico do jornal, conforme lembra Zavam (2009, p. 182). O gênero Editorial, segundo a autora, "ocupa um lugar discursivo assegurado para a manifestação axiológica da empresa jornalística" (ZAVAM, 2009, p. 182). A esse propósito mais geral, está, então, articulado um conteúdo mais geral: manifestar opiniões acerca de um tema, sobre o qual o Editorial firma seu posicionamento (cf. ZAVAM, 2009, p. 182).

Os parênteses com foco no escrevente, por sua vez, apresentam duas funções no sentido de manifestar um posicionamento da voz coletiva do jornal em relação ao conteúdo tópico: (i) qualificação do escrevente para discorrer sobre o tópico (cf. (14a)), e (ii) manifestações atitudinais do escrevente em relação ao tópico (cf. (14b)).

(14) a) Para saudar essa victoria do novo partido, | para a qual tambem concorremos, intervindo | como elemento de formação da opinião, abri- | mos aqui espaço ao nosso illustre collega do | Paiz. (A Província de São Paulo, 1885)

b) O serviço que desagrada e levanta re- | clamações não é mal feito por má vonta- | de dos empregados, justiça se lhes faça, | mas por deficiencia de pessoal. (A Província de São Paulo, 1882)

Parênteses como o de (14a) suspendem o tópico discursivo em curso para que o escrevente insira um comentário avaliativo de sua competência para desenvolver esse tópico; no exemplo em (14a), a suspensão do tópico é operada para que o escrevente do editorial qualifique positivamente a imagem do jornal como participante das eleições e elemento de formação de opinião. Jubran (2006b, p. 341) prevê que essas avaliações podem ser positivas (autoqualificação) ou negativas (autodesqualificação). Entre as 132 ocorrências coletadas, apenas 
quatro (3\% dos dados) configuram-se como parênteses qualificadores do escrevente para discorrer sobre o tópico, e todas manifestam uma autoqualificação do escrevente para discorrer sobre o tópico discursivo em curso.

Esse resultado revela traços da autoria do Editorial em jornais paulistas do século XIX. Zavam (2009) afirma que a autoria dos Editoriais cearenses ao longo dos séculos XIX e XX é bastante institucionalizada, de modo a se atribuir a responsabilidade discursiva à instância empresarial ou política dirigente do jornal. Segundo a autora, o uso da primeira pessoa do plural, como ocorre em (14a), configura um mecanismo de impessoalização, tipicamente encontrado em Editoriais cearenses do século XIX. Assim, um dado como (14a), em que se expressa uma autoqualificação e se faz uso da primeira pessoa do plural, marca essa autoria institucional a que se refere Zavam (2009), em que "o editorialista, que não responde diretamente às intervenções dos leitores e é contratado para manifestar opiniões que a empresa espera que sejam manifestadas, goza de prestígio.” (ZAVAM, 2009, p. 192)

Já parênteses como o de (14b) exprimem "o modo pelo qual o significado dos enunciados tópicos é qualificado, de forma a refletir o julgamento do falante sobre a probabilidade de serem verdadeiras as proposições expressas por ele" (JUBRAN, 2006b, p. 343). Em (14b), por exemplo, o sujeito da enunciação se envolve com o enunciado ali instaurado de modo a fazer justiça, ou ser justo, com a afirmação inserida naquele tópico discursivo, e a suspensão do tópico do enunciado se opera de modo a manifestar essa modalização do escrevente em relação a seu enunciado. O predomínio desse tipo de parênteses (25 ocorrências entre as 132 totais, o que representa $18,7 \%$ dos dados), entre os parênteses que focam o escrevente, é compatível com a parcialidade e a subjetividade características do Editorial, uma vez que esse gênero, longe de ser imparcial e objetivo, intenciona, de fato, reproduzir um posicionamento discursivo do jornal sobre a temática abordada.

Os dados em (15), junto a (14b), ajudam a perceber como os parênteses que focalizam o escrevente colaboram na construção de um posicionamento político e opinativo dos Editoriais paulistas oitocentistas. Além disso, esses dados mostram como os Editoriais aqui analisados detêm uma motivação político-partidária, o que se conforma a uma tendência assinalada por Zavam (2009) em relação aos jornais cearenses: segundo a autora, questões político-partidárias motivavam fortemente 
a circulação dos jornais cearenses do século XIX e do início do século $\mathrm{XX}$; os Editoriais desses jornais configuravam instrumentos de ataques, por parte de seus redatores, a adversários políticos.

(15) a) Fez-se, ainda ha pouco, a eleição para $\mid$ deputados e senadores ao Congresso Na- | cional: e, sem que desejemos atirar uma | censura aos directores dessa eleição, não | podemos deixar de reconhecer que elles $\mid$ não conseguiram dar ao seu grande e | inegavel triumpho material a força mo- | ral que era precisa na primeira mani- | festação da vontade popular dentro do | regimen republicano. (A Província de São Paulo, outubro de 1890)

b) Não julgamos a idéa contraria á politica | conservadora e, si não nos enganamos, os $\mid$ conservadores de Pernambuco não lhe são $\mid$ adversos e antes a defendem. (A Província de São Paulo, fevereiro de 1879)

Em (15a-b), os fatos parentéticos, ao manifestarem no texto uma atitude subjetiva do escrevente, ajudam a reforçar seu direcionamento crítico e político-partidário. Em (15a), por exemplo, ao discorrer sobre a eleição para deputados e senadores ao Congresso Nacional, o jornal, instituído no segmento parentético pelo uso da primeira pessoa (desejemos), não somente informa sobre os fatos levados a cabo pelos diretores da eleição, mas envolvem-se subjetivamente com esse conteúdo tópico, atacando a imagem desses diretores. Já em (15b), o segmento parentético si não nos enganamos modaliza o posicionamento do jornal (novamente presente, de forma institucional, pelo uso da primeira pessoa do plural), manifestando seu descomprometimento com a veracidade do que ali está sendo relatado.

Por fim, em (16), dispõem-se parênteses de baixa ocorrência no corpus, que correspondem a três classes distintas: parênteses com foco no escrevente (cf. (16a)), parênteses com foco no interlocutor (cf. (16bc)) e parênteses focalizadores do ato comunicativo (cf. (16d)). 
(16) a) O sr. conselheiro Carrão deputado por $\mid \mathrm{S}$. Paulo, apreciando as theorias do sr. Za- | charias, chegou a affirmar que o Brazil se | achava em circumstancias em que o poeta | latino descreveu os Gregos:

$<<$ Quidquid delirant reges plectuntur Achivi. $>>$ $<<$ Declaro, dizia o illustre paulista na ses- $\mid$ são de 8 de Julho de 1864, que não compre- | hendo bem qual é a politica do governo, não $\mid$ comprehendo quaes são suas idéas. (A Província de São Paulo, 1880)

b) Passando a ser $\mid$ propriedade da Companhia Impressora, | O Estado de S. Paulo, como terá obser- | vado o publico, não abdicou as suas tra- $\mid$ dicções de independencia, de liberdade, | e de insubmissão a quaesquer interesses | particulares contrários aos da collectivi- | dade paulista; conserva-se como o dei- | xou o seu patriotico fundador. (A Província de São Paulo, janeiro de 1891)

c) $\mathrm{O}$ acto hoje violentamente estygmati- $\mid$ sado não é senão a conseqüência daquel- | le que, sem um unico motivo, tirou o | governo de S. Paulo de seus legitimos | depositarios;

O dr. Jorge Tibiriçá tinha por si a | adhesão unânime dos paulistas;

O dr. Americo Brasiliense é um sim- | ples detentor do governo de S. Paulo;

Cabe-nos uma grande parte da vergo- $\mid$ nha que actualmente pesa sobre o Es- | tado.

Tudo isto- se assim o querem- é: | pura verdade. (A Província de São Paulo, agosto de 1891)

d) O mais operoso, o mais assiduo e o $\mid$ mais brilhante redactor do Commercio | de S. Paulo, o illustre sr. José Julio Rodrigues-a quem enviamos cordiaes cum- | primentos, por que é a primeira vez que | nos encontramos-acaba de publicar, na- | quella folha, um artigo que não deve $\mid$ circular sem alguns comentarios. (A Província de São Paulo, janeiro de 1893) 
O parêntese em (16a), tipo muito pouco frequente entre os dados coletados (três ocorrências no total, o que representa 2,3\% dos dados), indica de quem é a autoria de alguma informação referida no texto e, assim, configura um segmento parentético com a função de indicar a fonte enunciadora do discurso.

Já em (16b), o parêntese em negrito evoca um conhecimento partilhado entre escrevente e destinatário(s), isto é, entre os envolvidos no ato comunicativo. Trata-se de um mecanismo de dar como consenso o conhecimento do tópico, o que se atesta pela presença explícita, materializada no sintagma nominal o público, do destinatário do Editorial. Por outro lado, em (16c), ao focar também os destinatários do Editorial, o escrevente deseja envolvê-los em seus comentários e avaliação a respeito do assunto abordado. No parágrafo anterior ao segmento E1E2-E3, o escrevente do Editorial atribui a culpa da situação política relatada à população de um modo geral, o que se evidencia pelo uso do pronome clítico de primeira pessoa do plural (nos) junto ao verbo caber. O segmento parentético se assim o querem, além de marcado por um caráter hipotético pela conjunção se, faz uso da terceira pessoa do plural, que, excluindo o eu da enunciação, no caso o escrevente, traz para o texto a presença dos destinatários do Editorial.

Por fim, em (16d), o parêntese em negrito dá sinais, no texto, da interferência de dados externos ao ato comunicativo. De certa forma, ele materializa a presença do escrevente pelo uso da primeira pessoa do plural (enviamos) e particulariza um potencial destinatário do Editorial (o sr. José Julio Rodrigues), fazendo referência a um evento externo ao ato comunicativo que constitui o Editorial (o de enviar cordiais cumprimentos).

Inserções parentéticas como (16b-d) ocorrem uma única vez, cada uma, entre todos os dados coletados. Seguindo Zavam (2009), essas inserções podem ser consideradas mecanismos que, ao lado dos parênteses focalizadores do escrevente exemplificados em (14) e (15), marcam a subjetividade e a parcialidade que fogem ao controle do editorialista. Nas palavras de Zavam (2009, p. 190):

Se quem escreve o editorial é um sujeito (entidade física, e não a instituição, entidade abstrata), que tem a tarefa de tomar partido sobre um fato da atualidade políticoeconômica e assim "aconselhar e dirigir a opinião dos leitores” (BELTRÃO, 1980, p. 60), inevitavelmente seu discurso será atravessado pela subjetividade e parcialidade $[\ldots]$. 
Em síntese, no tocante a sua funcionalidade, a Parentetização está associada a dois principais aspectos da constituição do gênero Editorial: (i) a representação de um posicionamento crítico do jornal e (ii) a institucionalização de uma autoria, que representa a voz do jornal, e não uma voz particular.

\section{Considerações finais}

Este artigo toma como proposta central oferecer uma análise textual-interativa das inserções parentéticas encontradas em Editoriais paulistas do século XIX. Para atender a esse objetivo mais geral, seguemse duas etapas de investigação: (i) descrição do modo como se configuram formalmente as inserções parentéticas nos Editoriais analisados, e (ii) caracterização da funcionalidade textual-interativa dos parênteses nesse gênero específico.

Em relação a (i), este trabalho evidencia que a materialidade escrita do tipo de gênero analisado influi na configuração formal dos parênteses: por um lado, o uso de conectivos e de marcas gráficas na delimitação dos parênteses chama a atenção para um traço que parece ser típico de modalidades textuais mais próximas ao pólo da escrita (dentro de um contínuo fala-escrita, conforme estabelecido em Marcuschi, 2001); por outro lado, a ocorrência de parênteses em fronteiras de constituintes da frase ou entre unidades frasais não implica rupturas ou descontinuidades sintáticas. Esses aspectos estão intrinsicamente relacionados à atividade de planejamento envolvida na formulação e na construção de um texto escrito prototípico, o que se sumariza nas seguintes palavras de Jubran (2006b, p. 357):

Pelo fato de que na escrita o modus sintático prevalece sobre o pragmático, nela não é de se esperar a ocorrência de parênteses que promovam cortes sintáticos, nem que se intercalem em determinadas fronteiras em que uma inserção poderia romper estruturas canônicas.

Além disso, os dados analisados apontam para uma revisão (ou implementação) em relação à proposta de Jubran (2006b) de que a ausência de partículas conetivas prefaciando os parênteses é uma evidência da propriedade de desvio tópico. A análise aqui apresentada possibilita concluir que os conectivos funcionam como suportes para o 
funcionamento textual-interativo das inserções parentéticas e não afetam o seu desvio tópico, já que muitas de suas construções são estruturalmente independentes ou desgarradas.

Já em relação a (ii), é possível traçar uma correlação em três vias entre traços composicionais do gênero Editorial (em circulação no século XIX em São Paulo) e a ocorrência predominante de determinadas classes e funções de parênteses: (a) o predomínio da classe parentética com foco no conteúdo tópico está relacionado a um dos atributos fundamentais do Editorial, a condensabilidade (BELTRÃO, 1980); (b) entre os parênteses com foco no conteúdo tópico, a alta frequência das funções esclarecimento e ressalva se articula à finalidade comunicativa do Editorial, no caso a defesa de um posicionamento crítico do jornal; (c) a ocorrência, mesmo que baixa, de parênteses com foco no escrevente, com foco no interlocutor e com foco no ato comunicativo, além de dar indícios de uma autoria, contribui para a construção da parcialidade e da subjetividade do Editorial.

Enfim, a análise do processo de Parentetização nos Editoriais do corpus selecionado mostra que esse processo é ocorrente e que suas funções se mostram significativas para a caracterização desse gênero à medida que contribuem com o propósito comunicativo central do Editorial: informar sem a preocupação de ser imparcial e objetivo, mas, ao contrário, ao trazer a informação, marcar o posicionamento do jornal em relação ao que se está informando.

\section{Referências}

BELTRÃO, Luiz. Jornalismo opinativo. Porto Alegre: Sulina, 1980.

DECAT, M. B. N. Orações adjetivas explicativas no português brasileiro e no português europeu: aposição rumo ao "desgarramento". SCRIPTA, Belo Horizonte, v. 5, n. 9, p.104-118, jul./dez. 2001.

DECAT, M. B. N. Por uma abordagem da (in)dependência de cláusulas à luz da noção de "unidade informacional". SCRIPTA, Belo Horizonte, v. 2, n. 4, p. 23-38, jan./jun. 1999.

JUBRAN, C. C. A. S. Introdução - A perspectiva textual-interativa. In: JUBRAN, C. C. A. S.; KOCH, I. G. V. (Org.). Gramática do português culto falado no Brasil. Campinas: Editora da UNICAMP, 2006a. v. I: Construção do texto falado, p. 27-36. 
JUBRAN, C. C. A. S. Parentetização. In: JUBRAN, C. C. A. S.; KOCH, I. G. V. (Org.). Gramática do português culto falado no Brasil. Campinas: Editora da UNICAMP, 2006b. v. I: Construção do texto falado, p. 301357.

JUBRAN, C. C.A. S. Uma gramática textual de orientação interacional. In: CASTILHO, A. T.; MORAIS, M. A. T.; LOPES, R. E. V.; CYRINO, S. M. (Org.). Descrição, história e aquisição do português brasileiro. Campinas; São Paulo: Pontes; FAPESP, 2007. p. 313-327.

JUBRAN, C. C. A. S.; KOCH, I. G. V. (Org.). Gramática do português culto falado no Brasil. Campinas: Editora da UNICAMP, 2006. v. I: Construção do texto falado.

LOPES-DAMASIO, L. R.; JUBRAN, C. C. A. S. (Org.). A província de São Paulo/O Estado de São Paulo - Editoriais. Assis: Universidade Estadual Paulista, 2015. (material digitado)

MARCUSCHI, L. A. Produção textual, análise de gêneros e compreensão. São Paulo: Parábola, 2008.

MARCUSCHI, L.A. Da fala para a escrita: atividades de retextualização. São Paulo: Editora Cortez, 2001.

PENHAVEL, E. A multifuncionalidade do conectivo 'e'. Estudos Lingüísticos, São Paulo, v. 35, p. 647-656, 2006.

STASSI-SÉ, J. Subordinação discursiva no português à luz da gramática discursivo-funcional. 2012. 194 f. Tese (Doutorado em Estudos Linguísticos) - Instituto de Biociências, Letras e Ciências Exatas, Universidade Estadual Paulista, São José do Rio Preto, 2012.

ZAVAM, A. S. Por uma abordagem diacrônica dos gêneros do discurso à luz da concepção de tradição discursiva: um estudo com editoriais de jornal. 2009. 420 f. Tese (Doutorado em Linguística) - Programa de PósGraduação em Linguística, Universidade Federal do Ceará, Fortaleza, 2009. 